\title{
Nasal high flow treatment in preterm infants
}

\author{
Calum T. Roberts ${ }^{1,2^{*}}$ and Kate A. Hodgson ${ }^{1}$
}

\begin{abstract}
Nasal High Flow (HF) is a mode of 'non-invasive' respiratory support for preterm infants, with several potential modes of action, including generation of distending airway pressure, washout of the nasopharyngeal dead space, reduction of work of breathing, and heating and humidification of inspired gas. HF has several potential advantages over continuous positive airway pressure (CPAP), the most commonly applied form of non-invasive support, such as reduced nasal trauma, ease of use, and infant comfort, which has led to its rapid adoption into neonatal care. In recent years, HF has become a well-established and commonly applied treatment in neonatal care.

Recent trials comparing HF and CPAP as primary support have had differing results. Meta-analyses suggest that primary HF results in an increased risk of treatment failure, but that 'rescue' CPAP use in those infants with HF failure results in no greater risk of mechanical ventilation. Even in studies with higher rates of HF failure, the majority of infants were successfully treated with HF, and rates of important neonatal morbidities did not differ between treatment groups. Importantly, these studies have included only infants born at $\geq 28$ weeks' gestational age (GA). The decision whether to apply primary HF will depend on the value placed on its advantages over CPAP by clinicians, the approach to surfactant treatment, and the severity of respiratory disease in the relevant population of preterm infants.

Post-extubation HF use results in similar rates of treatment failure, mechanical ventilation, and adverse events compared to CPAP. Post-extubation HF appears most suited to infants $\geq 28$ weeks; there are few published data for infants below this gestation, and available evidence suggests that these infants are at high risk of HF failure, although rates of intubation and other morbidities are similar to those seen with CPAP. There is no evidence that using HF to 'wean' off CPAP allows for respiratory support to be ceased more quickly, but given its advantages it would appear to be a suitable alternative in infants who require ongoing non-invasive support. Safety data from randomised trials are reassuring, although more evidence in extremely preterm infants ( $<28$ weeks' GA) is required.
\end{abstract}

Keywords: Nasal high flow, Continuous positive airway pressure, Non-invasive ventilation, Infant, premature

\section{Background}

Respiratory distress syndrome (RDS) and sequelae such as bronchopulmonary dysplasia (BPD) are substantial contributors to adverse outcomes in preterm infants. The use of 'non-invasive' respiratory support (without an endotracheal tube) is one strategy clinicians have adopted to improve management of these conditions. For several decades, nasal continuous positive airway pressure (CPAP) has been the principal mode of noninvasive respiratory support for preterm infants. CPAP is

\footnotetext{
* Correspondence: calum.roberts@thewomens.org.au

'Newborn Research Centre, The Royal Women's Hospital, Locked Bag 300, Flemington Road, Parkville 3052, Melbourne, VIC, Australia

${ }^{2}$ Department of Obstetrics and Gynaecology, The University of Melbourne,

Melbourne, Australia
}

(c) The Author(s). 2017 Open Access This article is distributed under the terms of the Creative Commons Attribution 4.0 International License (http://creativecommons.org/licenses/by/4.0/), which permits unrestricted use, distribution, and reproduction in any medium, provided you give appropriate credit to the original author(s) and the source, provide a link to the Creative Commons license, and indicate if changes were made. The Creative Commons Public Domain Dedication waiver (http://creativecommons.org/publicdomain/zero/1.0/) applies to the data made available in this article, unless otherwise stated.

effective as post-extubation support, [1] and as primary respiratory support (the first respiratory support applied after initial stabilisation). CPAP is a feasible and effective alternative to routine intubation and ventilation after birth, even for those infants born at $<28$ weeks' gestational age (GA) [2-5]. The use of CPAP as primary respiratory support may also improve long-term outcomes such as death or BPD, [6] and is recommended in current consensus guidelines for preterm infants with RDS [7].

While effective, CPAP does have some disadvantages: it requires the use of bulky interfaces, must be managed by highly skilled nursing staff to be effective, and has been associated with adverse outcomes, such as nasal trauma [8] and pneumothorax [3]. There is 
also significant heterogeneity of CPAP devices and interfaces, which may influence efficacy in research and clinical settings [9].

Interest in nasal High Flow (HF), an alternative mode of non-invasive respiratory support, has grown dramatically in recent years. HF treatment refers to the delivery of heated, humidified, blended air and oxygen, via small loose-fitting nasal cannulae (Fig. 1), at $>1$ Litre per minute $(\mathrm{L} / \mathrm{min})$ [10]. Initially $\mathrm{HF}$ was applied clinically without good quality evidence of efficacy and safety. However, the publication of several recent large randomised clinical trials has allowed clinicians to make more informed decisions about which infants can appropriately receive HF treatment [11-14].

\section{Mechanisms of action}

Several mechanisms of action for HF have been proposed, which can be summarised as follows: generation of distending pressure; 'washout' of the nasopharyngeal dead space; provision of gas flow sufficient to reduce inspiratory resistance and work of breathing; and provision of adequate gas conditioning [15].

\section{Distending pressure}

CPAP systems generate a continuous distending pressure, which is set and usually measured. In comparison, HF devices use a set gas flow, but do not target, or measure, the applied pressure. Early clinical studies of HF in neonates focused on measuring the distending pressure resulting from HF therapy, both as a proposed mechanism of action, and due to concern that application of an uncontrolled, potentially high pressure may lead to pulmonary over-distension. Studies have identified three key factors

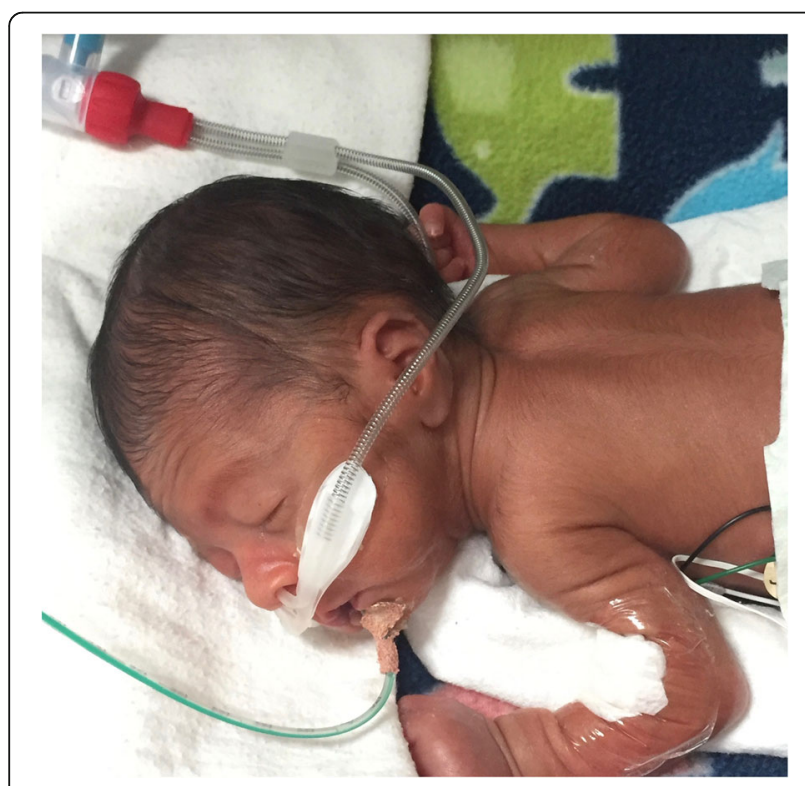

Fig. 1 A preterm infant receiving High Flow support that result in increased distending pressure during HF treatment: increasing gas flow, increased ratio of the diameter of the cannulae to that of the nares, and lower infant weight [16-18]. Appropriate sizing of the cannulae, such that there is a gas 'leak' around them in the nares, is an important aspect of applying $\mathrm{HF}$ safely. Studies in which the prongs are sized according to these recommendations have found that within the flow range currently applied in neonates (up to $8 \mathrm{~L} / \mathrm{min}$ ), upper airway pressures are similar to those routinely used with CPAP [19-21].

\section{Dead space washout}

The anatomical dead space is the volume of gas between external nares and terminal bronchioles, which usually has gas concentrations similar to the alveoli (i.e. higher carbon dioxide and lower oxygen concentrations than atmospheric air) [22]. In theory, the 'wash out' of the nasopharyngeal gas space by HF may reduce anatomical dead space and improve gas exchange, although data supporting this concept come mostly from lab and animal studies [15, 23]. A recent benchtop study, using a neonatal model with simulated spontaneous breathing, found that with the mouth closed, carbon dioxide washout times were significantly shorter with HF than with CPAP, although the two modes did not differ with the mouth open. The authors noted that this effect might be particularly important in more preterm infants, who have a high dead space-to-tidal volume ratio [24]. There are no in vivo data specifically supporting this mechanism of action from studies of neonatal patients.

\section{Work of breathing}

The nasopharynx has a relatively large surface area with resulting resistance to gas flow, which might be minimised by the use of HF to provide a gas flow at or above the peak inspiratory flow of the patient [15]. Physiological studies, using measures such as respiratory inductance plethysmography and diaphragmatic electrical activity, have generally supported the concept that work of breathing can be reduced by HF treatment. Results of comparisons with CPAP however have been conflicting, with some studies finding HF to be of similar efficacy, [25-27] and others finding CPAP more effective $[28,29]$.

\section{Gas conditioning}

Delivery of unconditioned gases can have a number of adverse effects on respiratory function, including impaired mucociliary function and thickening of secretions, damage to the airway mucosa, [30-32] and a reduction in pulmonary compliance and functional residual capacity [33]. Furthermore, heating and humidification of environmental gas by the upper airway mucosa is associated with both caloric and evaporative heat loss, [34] 
and can result in hypothermia, factors that are all specifically important to preterm infants [35-37]. Therefore, appropriate gas conditioning has been postulated as a potential benefit resulting from HF treatment [15]. Lab studies have found HF devices to produce absolute humidity levels similar to, or slightly below, those achieved by CPAP devices $[38,39]$. Whether these differences are clinically significant is unclear.

\section{Advantages of high flow}

The perception that HF has several advantages over CPAP, and is a 'less invasive' mode of therapy, was a major contributory factor in the growth of its use in neonatal units. In surveys conducted in Australia and the UK, cited benefits included reduced nasal trauma, increased infant comfort, easier access for parental feeding and skin-to-skin care, and ease of set-up and use for staff [40-42]. Over time, evidence has accumulated to support the veracity of many of these perceived benefits.

The majority of HF randomised controlled trials (RCTs) have shown a reduction in nasal trauma with HF in comparison with CPAP, [11, 12, 14, 43, 44] although two showed no difference in trauma rates $[45,46]$. The Cochrane Review included pooled analyses of several of these studies: as post-extubation treatment HF was associated with a significant reduction in nasal trauma versus CPAP (RR 0.64, 95\% confidence interval [CI] 0.51, 0.79), but as primary respiratory support the difference was not significant (RR 0.62, 95\% CI 0.34, 1.15) [10].

Of two studies to assess patient comfort using validated scales, one showed no difference in pain score between HF and CPAP, [47] whereas a second found HF infants to have significantly lower pain scores and salivary cortisol levels [48].

Another perceived advantage is that HF better enables oral feeding, specifically for infants attempting to breastfeed. However, neither individual RCTs, nor pooled analysis, have demonstrated any advantage in feeding outcomes with HF support [14, 46, 49, 50]. Non-randomised studies suggest that oral feeds can be introduced in infants receiving HF [51, 52].

Studies in both the lab and clinical setting indicate that noise levels produced by HF are generally greater than, or similar to, those produced by CPAP $[53,54]$.

Studies that have more systematically assessed the response of parents and nursing staff have borne out initial reports that they find HF preferable to CPAP. Klingenberg et al. [47] reported that parents scored HF significantly higher in three domains: their child's satisfaction, contact and interaction, and parental ability to take part in infant care. A single-centre survey of neonatal nurses revealed that they preferred HF to CPAP for infants of 28 weeks' GA and above, believing it to be easier to set up and use, less likely to cause nasal trauma, more comfortable, and preferred by parents [55].

HF might also present the advantage of reduced cost, although there are currently few data to support this. A 2016 systematic review and economic evaluation performed by the National Institute for Health Research (UK), based on the results of four post-extubation RCTs, concluded that there was insufficient evidence to indicate whether HF treatment is cost-effective [56].

\section{Primary respiratory support}

Prior to 2016, there was little published evidence from RCTs assessing the role of HF as primary respiratory support. Available data came from small studies, each including approximately 70 infants, $[43,46]$ and a subgroup of a larger trial that principally assessed postextubation support. [14] Meta-analyses published in 2015 and 2016, including infants from these 4 studies, found no differences in treatment failure, intubation, or other important outcomes, and concluded that further adequately powered studies were required $[10,57]$. The latter half of 2016 saw the publication of two larger studies, of differing methodology, designed to better evaluate primary HF.

A single-centre Italian study by Lavizzari et al. [49] randomised 316 preterm infants, of mean GA 33 weeks and birth weight $1.9 \mathrm{~kg}$, to primary treatment with either $\mathrm{HF}$, or CPAP/biphasic positive airway pressure (BiPAP). The primary outcome was treatment failure within $72 \mathrm{~h}$, defined as the need for mechanical ventilation. The study allowed infants to receive intubation, surfactant treatment, and extubation (INSURE treatment), without regarding them as having treatment failure. The authors found similar rates of treatment failure $(10.8 \%$ with $\mathrm{HF}$ and $9.5 \%$ with CPAP/BiPAP), with resultant risk difference (RD) 1.3\% (one-sided 95\% CI -6.0, 8.6), and concluded that HF was non-inferior to CPAP/BiPAP, relative to their specified non-inferiority margin of 10 percentage points. Despite the relatively low treatment failure rates, surfactant administration was common, occurring in $>40 \%$ of infants in both treatment groups. Other outcomes did not differ significantly between treatment groups.

The authors acknowledged that their centre had relatively limited HF experience, and that treatment allocation could not be blinded. Other limitations included that the age at randomisation was not reported, and it was unclear if patients received respiratory support before randomisation took place. Furthermore, the trial was not prospectively registered in a clinical trials registry, and preliminary data from this trial had previously been published part way through recruitment, [58] so 
the authors were unblinded to the study outcomes, creating a risk of bias.

The HIPSTER trial, [13] led by our research group, included 564 infants of mean 32 weeks' GA and $1.7 \mathrm{~kg}$; infants had not received surfactant treatment and were median $1.4 \mathrm{~h}$ of age at randomisation. The study was designed to assess non-inferiority of HF, with a margin of $10 \%$, but was stopped early on the advice of the independent safety monitoring committee due to a highly significant difference in the primary outcome: treatment failure within $72 \mathrm{~h}$, defined by objective oxygenation, blood gas, apnoea and intubation criteria. Infants received surfactant treatment only after meeting treatment failure criteria.

Treatment failure occurred significantly more frequently in the HF infants $(25.5 \%$ vs. $13.3 \%$; RD $12.3 \%$, 95\% CI 5.8 to 18.7), but infants with HF failure could receive 'rescue' CPAP prior to intubation, and the resulting intubation rates were similar in the two treatment groups (15.5\% vs. $11.5 \%$; RD $3.9 \%, 95 \%$ CI -1.7 to 9.6 ). Again, blinding of the two treatments was not possible, and just over half of infants received a brief period of CPAP (median $1.5 \mathrm{~h}$ ) prior to randomisation, which could have influenced outcomes.

Recently, another RCT comparing HF and CPAP as primary support in a single Korean unit was published [59]. This study included 85 of 87 randomised infants, mean 33 weeks' GA and $2.0 \mathrm{~kg}$, in a per-protocol analysis. Objective treatment failure criteria (respiratory acidosis, apnoea or hypoxia) were defined. Infants in both groups were permitted to receive nCPAP or bilevel CPAP at clinician discretion, prior to mechanical ventilation. Reported rates of treatment failure were $38.1 \%$ with HF compared to $20.9 \%$ with CPAP (RD $17.2 \%, 95 \%$ CI -1.9 to 36.2 ).

The higher rate of treatment failure seen in HF infants may be a reflection of the more consistent and slightly higher distending pressure produced by CPAP $[16,21]$. This is likely to be beneficial in infants with acute RDS, and may explain the difference in risk of treatment failure seen with HF in HIPSTER, and the findings of the Lavizzari and post-extubation studies, in which many infants had received surfactant prior to determination of the primary outcome.

There are now $>900$ additional infants randomised in trials of primary HF support since the Cochrane Review was published in early 2016. An updated pooled analysis of key outcomes from published RCTs comparing HF and CPAP is shown in Fig. 2. Ultimately, whether clinicians choose to apply HF as primary support for preterm infants will depend on several factors. Those who place a high value on HF's advantages (e.g. in units with high rates of nasal trauma associated with CPAP) may choose to use HF frequently, with the option of 'rescue' CPAP in those infants with HF failure. Those who have low rates of nasal trauma, or deal with populations with more severe RDS (e.g. those with low rates of antenatal steroid exposure) may prefer to use primary CPAP. Strategies to prospectively identify the infants most likely to be successfully treated with HF may facilitate wider use in this clinical setting. These studies have all included infants of 28 weeks' GA or higher, and primary HF use in infants of lower gestations is not recommended based on current evidence.

\section{Post-extubation support}

Early RCTs of post-extubation HF published between 2006 and 2010 (whether comparing HF and CPAP, or different HF devices) included relatively small study samples ( $\leq 40$ infants), and low gas flows in comparison to current practice $[44,60,61]$. In 2013, the publication of three larger RCTs significantly added to the evidence base for HF use. The first included 132 very preterm infants $(<32$ weeks' GA), who were randomised to either HF or CPAP at extubation [11]. Rates of extubation failure did not differ significantly (22\% in the HF group and $34 \%$ in the CPAP group), nor did rates of reintubation (17\% versus $24 \%$ respectively).

A similar study compared HF and CPAP using a noninferiority design, designating a RD for treatment failure of 20 percentage points as the margin of non-inferiority for HF treatment [12]. This trial included 303 very preterm infants, and treatment failure (defined by prespecified criteria) occurred in $34.2 \%$ of HF infants and $25.8 \%$ of CPAP infants; the RD for treatment failure with HF was $8.4 \%$ (95\% CI $-1.9,18.7)$, thereby meeting the defined non-inferiority margin. This study also included 'rescue' CPAP treatment for those infants with HF failure, with the result that approximately half of these infants avoided reintubation within 7 days: $17.8 \%$, versus $25.2 \%$ of CPAP infants. In those infants $<26$ weeks' GA, the risk of HF failure was particularly high $(81 \%)$ compared with $61 \%$ for CPAP. Although the 63 infants $<26$ weeks' GA represent a small sample, given the high rate of HF failure and 20 percentage point increase compared with CPAP, the authors advised caution with HF use in this group.

The third RCT included infants between 28 and 42 weeks' GA at birth. [14] Of the 432 infants included, 291 were randomised to HF or CPAP at extubation, and the primary outcome of reintubation within $72 \mathrm{~h}$ did not differ significantly between groups: $11.6 \%$ and $6.5 \%$ respectively.

A Cochrane Review, [10] updated in 2016, identified 6 published studies including 934 infants, who were randomised to either HF or CPAP as post-extubation support. Meta-analysis demonstrated that infants treated with HF were at no additional risk of treatment failure (typical risk ratio [RR] 1.21, 95\% CI 0.95 to 1.55), 


\section{a Treatment failure within $\mathbf{7 2}$ hours}

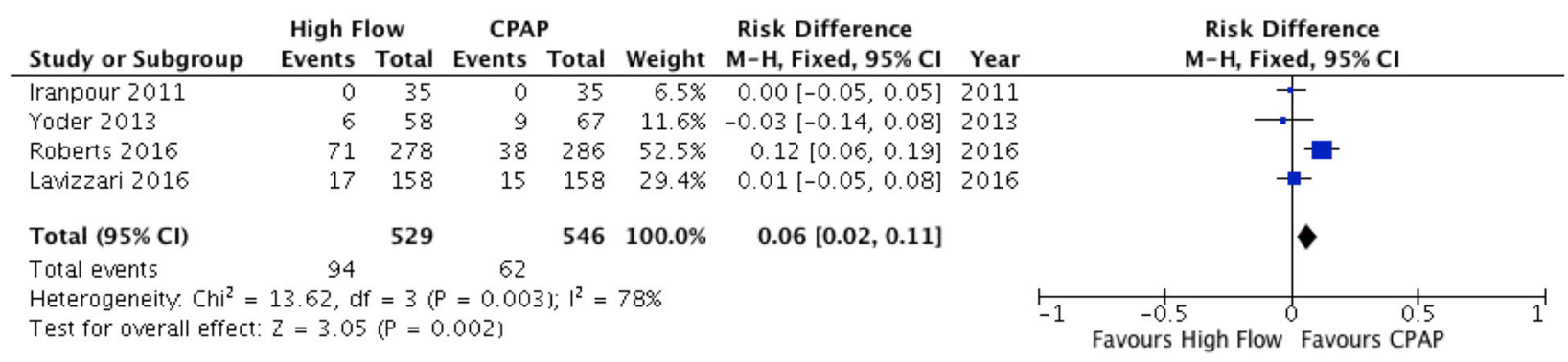

\section{b Intubation within 72 hours}

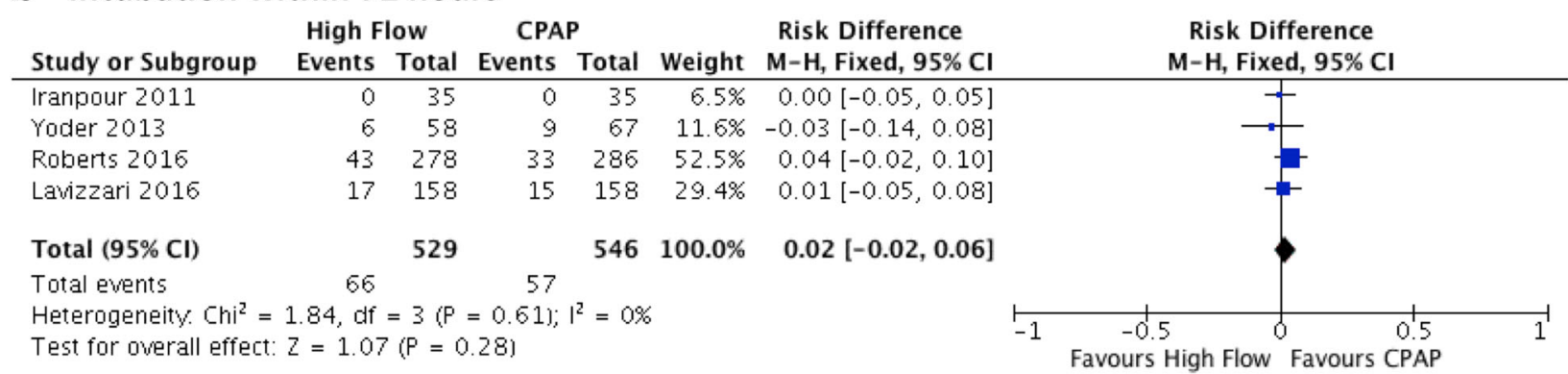

\section{Pneumothorax during hospital admission}

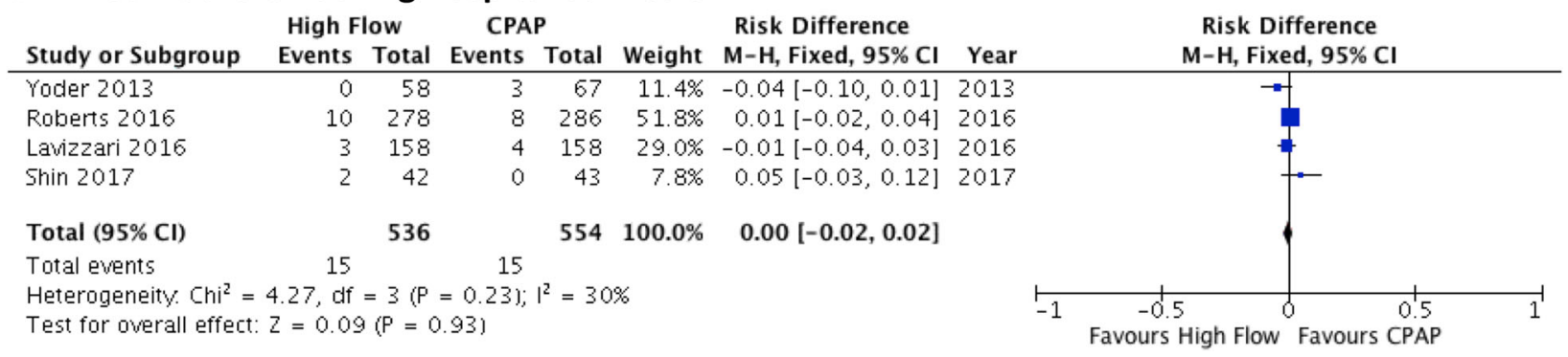

Fig. 2 Pooled analyses of published randomised trials comparing High Flow and CPAP as primary support for preterm infants, for the outcomes: a. Treatment failure within 72 h; b. Intubation within 72 h; c. Pneumothorax during hospital admission

reintubation (RR $0.91,95 \%$ CI 0.68 to 1.20 ), or other adverse outcomes including death or BPD. The Cochrane Review authors noted that RCTs thus far have included relatively few extremely preterm infants $(<28$ weeks' GA). Within the subgroup of infants from 28 to 32 weeks' GA, HF resulted in a RR $(95 \% \mathrm{CI})$ of 0.80 $(0.44,1.44)$ for treatment failure, and $0.51(0.27,0.97)$ for intubation in comparison to CPAP, suggesting that post-extubation HF (with the availability of rescue CPAP) may be a particularly appropriate strategy in this group of infants.

Three studies published since the Cochrane Review have included similar populations and methods to those previously published, and results were consistent with the previous Cochrane conclusions. Two studies showed similar rates of treatment failure and intubation with HF and CPAP, [62, 63] and the third small study found a higher rate of intubation in $\mathrm{HF}$ infants, although outcomes were reported for only half of the 108 infants randomised [64].

The available data seem to support the use of HF as an alternative to CPAP as post-extubation support for infants $\geq 28$ weeks' GA, but it is advised that 'rescue' CPAP, which prevented intubation of infants with HF failure in several studies, is available. Routine use of post-extubation HF in infants $<28$ weeks' GA should be approached with caution.

\section{Weaning from CPAP}

HF may also be used as a 'weaning' mode, to transition infants off CPAP support. Randomised trials assessing this approach have included far fewer infants than those assessing primary and post-extubation support, and have produced conflicting outcomes. One study found HF use to be associated with a significant increase in duration of oxygen therapy, and of respiratory support, in 
comparison to weaning directly from CPAP, [65] another found HF infants to have a significantly shorter duration of oxygen treatment and of hospital stay, [66] and other studies reported similar outcomes with either approach $[67,68]$. There is no convincing evidence that use of HF in this manner is beneficial in weaning infants from CPAP, although given its advantages, it may be viewed as an alternative to CPAP in those infants who continue to require non-invasive support.

\section{Safety and later outcomes of high flow}

The first major safety concern associated with HF therapy was an outbreak of infection with the Gramnegative species Ralstonia, resulting from contaminated humidifier cartridges in the Vapotherm 2000i device in 2005 [69]. Following the introduction of stricter infection control guidance by the manufacturer, there have been no further infection concerns since.

A further area of concern for clinicians, in keeping with the potential to generate high airway pressures discussed above, was the risk of over-distension and pulmonary air leak. Case reports of infants with complications including pneumothorax, pneumomediastinum, subcutaneous scalp emphysema, pneumocephalus and pneumo-orbitis gave some weight to these concerns [70-72]. Fortunately, available data from randomised trials have been reassuring, with no evidence of an increased pneumothorax risk with HF. The Cochrane Review in fact found a small reduction in the rate of pneumothorax (typical RD $-0.02,95 \%$ CI -0.03 to -0.00 ) in a pooled analysis of 896 infants from post-extubation studies. [10] Recent primary support trials have also reported similar rates of pneumothorax with HF and CPAP; a pooled analysis of these results is shown in Fig. $2[13,14,49,59]$.

Several RCTs have reported no increase in duration of support with HF, $[11,12,49,59]$ and in those that have, the difference has usually been small (1-2 days). $[13,14,46]$ There is no evidence from RCTs to suggest that HF treatment is associated with an increased risk of BPD or death, either as individual or combined outcomes. Nor have these studies shown an increase in duration of hospitalisation, or other important clinical outcomes [10-14, 43, 49, 59].

Recent publications based on non-randomised data have raised concerns about the effect of HF use on respiratory outcomes, $[73,74]$ in particular prolonged respiratory support and BPD. However, limitations such as differing demographics in infants treated with HF, inconsistencies in the definition of BPD, and changes in practice during the study period, mean that these data do not allow firm conclusions to be drawn. HF is commonly applied after mechanical ventilation and/or CPAP, $[75,76]$ and it is conceivable that the infants receiving HF in these studies were those with the most significant lung disease, who required the most prolonged respiratory support. However, there are relatively few extremely preterm infants included in RCTs, and further research in this population is required. Exposure to prolonged respiratory support may be influenced in part by the approach to weaning HF applied by clinicians, and care should be taken to avoid unnecessarily prolonging support when weaning or cessation of treatment may be possible.

\section{Use in neonatal units}

HF devices were incorporated into neonatal care before good quality RCT data were available to guide their use. The Vermont Oxford Network reported that HF use in infants born between 501 and $1500 \mathrm{~g}$ increased from $45 \%$ to $58 \%$ between 2006 and 2009 [77]. Surveys conducted between 2009 and 2011 showed HF to be in use in the majority of UK and Australasian NICUs, with the majority using gas flows of $\leq 8 \mathrm{~L} / \mathrm{min}[40,42,78]$. Concerningly in one UK survey, half of units stated that they selected the cannulae size that best fit the nostrils, rather than allowing a gas 'leak' around the prongs, which is an important safety mechanism. Many units also had no written HF guideline or policy in place [42]. Common reasons for HF use in Australian and UK units were as an alternative to CPAP, to wean from CPAP, and as postextubation support [40].

Data reported from the 56 neonatal units in The Australian and New Zealand Neonatal Network (ANZNN) show that HF use increased from $8 \%$ of NICU registrants in 2009, to $27 \%$ in 2014. [79] HF use was most common in infants born at $<28$ weeks' GA. Amongst all very preterm infants from 2009 to 2012, HF was commenced at a median 17 days of age, and the majority of infants had received CPAP (90\%), endotracheal ventilation $(71 \%)$, or both (64\%) prior to HF, with primary HF use being rare (2\% of infants) [75].

More recent publications indicate further growth in HF use in the UK, [76] use in the majority of Japanese NICUs, [80] and the introduction of HF use during neonatal inter-hospital transport [81].

\section{Future research directions}

There remain several areas of HF practice in which further evidence is needed. Given the concerns raised about prolonged exposure to respiratory support, studies assessing the best approach to weaning and ceasing $\mathrm{HF}$ should be conducted. Extremely preterm infants, who are those at greatest risk of BPD, should be further studied, to ensure that HF use is not associated with important adverse outcomes.

Studies thus far have evaluated HF at the gas flows suggested by device manufacturers, which are currently a maximum of $8 \mathrm{~L} / \mathrm{min}$ in the neonatal population. 
Given that evidence suggests adverse events (particularly pneumothorax) at these flows are rare, there is the possibility to study the use of higher gas flows, which may produce a greater distending pressure, potentially beneficial in conditions such as RDS. Some clinicians continue to report an anecdotal preference for one HF device over another and, with the exception of a single underpowered study, [61] there has been little research in this area. HF may be of value as a method of stabilisation in the delivery room, as reported in a small observational study of infants $<30$ weeks' GA at birth, [82] but this has yet to be assessed in a randomised trial.

The available RCT evidence for neonatal HF use relates exclusively to NICUs, but HF use in non-tertiary neonatal units is commonly reported, and increasing. A multi-centre RCT comparing HF and CPAP in Australian non-tertiary neonatal units is currently underway (ACTRN12614001203640).

\section{Conclusions}

High Flow is now well established as an important part of neonatal respiratory care, and has a number of potential benefits for preterm infants. While it appears that HF can be applied successfully as primary support for many infants $>28$ weeks' GA, it is less effective than CPAP in preventing treatment failure, and factors such as severity of RDS in the treated population, and approach to surfactant should be considered. The evidence suggests that post-extubation HF is suitable for infants $>28$ weeks' GA. The availability of rescue CPAP is an important part of the treatment pathway in both primary and post-extubation use, ensuring infants treated with $\mathrm{HF}$ are not at increased risk of intubation. Research into the optimal approach to weaning HF, and its use in extremely preterm infants, is required to ensure it is applied in such a way that produces maximal benefit for infants and their families, whilst avoiding unintended adverse effects.

\section{Acknowledgements}

CR acknowledges the support of The University of Melbourne Henry and Rachael Ackman Travelling Scholarship.

\section{Funding}

The authors have no sources of funding to declare.

\section{Availability of data and materials}

Not applicable.

\section{Authors contributions}

CR prepared the first draft of the manuscript, which was reviewed and revised by $\mathrm{KH}$. Both authors read and approved the final manuscript.

\section{Ethics approval and consent to participate}

Not applicable.

\section{Consent for publication}

The patient image included with this article is used with parental consent.

\section{Competing interests}

The authors declare that they have no competing interests.

\section{Publisher's Note}

Springer Nature remains neutral with regard to jurisdictional claims in published maps and institutional affiliations.

Received: 25 April 2017 Accepted: 29 August 2017

Published online: 06 September 2017

\section{References}

1. Davis PG, Henderson-Smart DJ. Nasal Continuous Positive Airways Pressure Immediately After Extubation For Preventing Morbidity In Preterm Infants. Cochrane Database Syst Rev 2003, Issue 2. Art. No.Cd000143. doi:10.1002/14651858.CD000143.

2. Dunn MS, Kaempf J, De Klerk A, et al. Randomized trial comparing 3 approaches to the initial respiratory management of preterm neonates. Pediatrics. 2011;128:E1069-76.

3. Morley CJ, Davis PG, Doyle LW, et al. Nasal CPAP or intubation at birth for very preterm infants. N Engl J Med. 2008;358:700-8.

4. Support Study Group of the Eunice Kennedy Shriver NICHD Neonatal Research Network, Finer NN, Carlo WA, et al. Early CPAP versus surfactant in extremely preterm infants. N Engl J Med. 2010;362:1970-9.

5. Sandri F, Plavka R, Ancora G, et al. Prophylactic or early selective surfactant combined with NCPAP in very preterm infants. Pediatrics. 2010;125:E1402-9.

6. Schmolzer GM, Kumar M, Pichler G, Aziz K, O'Reilly M, Cheung PY. Noninvasive versus invasive respiratory support in preterm infants at birth: systematic review and meta-analysis. BMJ. 2013;347:F5980.

7. Sweet DG, Carnielli V, Greisen G, et al. European consensus guidelines on the management of neonatal respiratory distress syndrome in preterm infants-2013 update. Neonatology. 2013;103:353-68.

8. Fischer C, Bertelle V, Hohlfeld J, Forcada-Guex M, Stadelmann-Diaw C, Tolsa JF. Nasal trauma due to continuous positive airway pressure in neonates. Arch Dis Child Fetal Neonatal Ed. 2010;95:F447-51.

9. De Paoli AG, Davis PG, Faber B, Morley CJ. Devices And Pressure Sources For Administration Of Nasal Continuous Positive Airway Pressure (Ncpap) In Preterm Neonates. Cochrane Database Syst Rev 2008, Issue 1. Art. No: Cd002977. doi:10.1002/14651858.CD002977.pub2.

10. Wikinson D, Andersen C, O'Donnell CP, De Paoli AG, Manley BJ. High flow nasal cannula for respiratory support in preterm infants. Cochrane Database Syst Rev. 2016, Issue 2. Art. No: CD006405.doi: 10.1002/14651858.CD006405.pub3.

11. Collins CL, Holberton JR, Barfield C, Davis PG. A randomized controlled trial to compare heated humidified high-flow nasal cannulae with nasal continuous positive airway pressure postextubation in premature infants. J Pediatr 2013; 162:949-954 E1.

12. Manley BJ, Owen LS, Doyle LW, et al. High-flow nasal cannulae in very preterm infants after extubation. N Engl J Med. 2013;369:1425-33.

13. Roberts $C T$, Owen $L S$, Manley BJ, et al. Nasal high-flow therapy for primary respiratory support in preterm infants. N Engl J Med. 2016:375:1142-51.

14. Yoder BA, Stoddard RA, Li M, King J, Dirnberger DR, Abbasi S. Heated, humidified high-flow nasal cannula versus nasal CPAP for respiratory support in neonates. Pediatrics. 2013;131:E1482-90.

15. Dysart K, Miller TL, Wolfson MR, Shaffer TH. Research in high flow therapy: mechanisms of action. Respir Med. 2009;103:1400-5.

16. Kubicka ZJ, Limauro J, Darnall RA. Heated, humidified high-flow nasal cannula therapy: yet another way to deliver continuous positive airway pressure? Pediatrics. 2008;121:82-8.

17. Spence KL, Murphy D, Kilian C, McGonigle R, Kilani RA. High-flow nasal cannula as a device to provide continuous positive airway pressure in infants. J Perinatol. 2007;27:772-5.

18. Wilkinson DJ, Andersen CC, Smith K, Holberton J. Pharyngeal pressure with high-flow nasal cannulae in premature infants. J Perinatol. 2008;28:42-7.

19. Collins $\mathrm{CL}$, Holberton JR, Konig K. Comparison of the pharyngeal pressure provided by two heated, humidified high-flow nasal cannulae devices in premature infants. J Paediatr Child Health. 2013;49:554-6.

20. Hasan RA, Habib RH. Effects of flow rate and airleak at the nares and mouth opening on positive distending pressure delivery using commercially available high-flow nasal cannula systems: a lung model study. Pediatr Crit Care Med. 2011;12:E29-33.

21. Lampland AL, Plumm B, Meyers PA, Worwa CT, Mammel MC. Observational study of humidified high-flow nasal cannula compared with nasal continuous positive airway pressure. J Pediatr. 2009;154:177-82. 
22. Van Hove SC, Storey J, Adams C, et al. An experimental and numerical investigation of $\mathrm{CO}_{2}$ distribution in the upper airways during nasal high flow therapy. Ann Biomed Eng. 2016;44:3007-19.

23. Frizzola M, Miller TL, Rodriguez ME, et al. High-flow nasal cannula: impact on oxygenation and ventilation in an acute lung injury model. Pediatr Pulmonol. 2011:46:67-74.

24. Sivieri Em, Foglia Ee, Abbasi S. Carbon Dioxide Washout During High Flow Nasal Cannula Versus Nasal Cpap Support: An In Vitro Study. Pediatr Pulmonol. 2017:52:792-98.

25. Lavizzari A, Veneroni C, Colnaghi M, et al. Respiratory mechanics during NCPAP and HHHFNC at equal distending pressures. Arch Dis Child Fetal Neonatal Ed. 2014;99:F315-20.

26. Saslow JG, Aghai ZH, Nakhla TA, et al. Work of breathing using high-flow nasal cannula in preterm infants. J Perinatol. 2006;26:476-80.

27. Shetty S, Hickey A, Rafferty GF, Peacock JL, Greenough A. Work of breathing during CPAP and heated humidified high-flow nasal cannula. Arch Dis Child Fetal Neonatal Ed. 2016;101:F404-7.

28. de Jongh BE, Locke R, Mackley A, et al. Work of breathing indices in infants with respiratory insufficiency receiving high-flow nasal cannula and nasal continuous positive airway pressure. J Perinatol. 2014;34:27-32.

29. Nasef N, El-Gouhary E, Schurr P, et al. High-flow nasal cannulae are associated with increased diaphragm activation compared with nasal continuous positive airway pressure in preterm infants. Acta Paediatr. 2015;104:E337-43

30. Hirsch JA, Tokayer JL, Robinson MJ, Sackner MA. Effects of dry air and subsequent humidification on tracheal mucous velocity in dogs. J Appl Physiol. 1975;39:242-6.

31. Konrad F, Schiener R, Marx T, Georgieff M. Ultrastructure and mucociliary transport of bronchial respiratory epithelium in intubated patients. Intensive Care Med. 1995:21:482-9.

32. Sleigh MA, Blake JR, Liron N. The propulsion of mucus by cilia. Am Rev Respir Dis. 1988;137:726-41.

33. Noguchi H, Takumi Y, Aochi O. A study of humidification in tracheostomized dogs. Br J Anaesth. 1973:45:844-8.

34. Sottiaux TM. Consequences of under- and over-humidification. Respir Care Clin N Am. 2006:12:233-52

35. Bickler PE, Sessler DI. Efficiency of airway heat and moisture exchangers in anesthetized humans. Anesth Analg. 1990;71:415-8.

36. Bissonnette B, Sessler DI. Passive or active inspired gas humidification increases thermal steady-state temperatures in anesthetized infants. Anesth Analg. 1989;69:783-7.

37. Stone DR, Downs JB, Paul WL, Perkins HM. Adult body temperature and heated humidification of anesthetic gases during general anesthesia. Anesth Analg. 1981;60:736-41.

38. Chang GY, Cox CA, Shaffer TH. Nasal Cannula, CPAP, and high-flow nasal cannula: effect of flow on temperature, humidity, pressure, and resistance. Biomed Instrum Technol. 2011;45:69-74.

39. Roberts CT, Kortekaas R, Dawson JA, Manley BJ, Owen LS, Davis PG. The effects of non-invasive respiratory support on oropharyngeal temperature and humidity: a neonatal manikin study. Arch Dis Child Fetal Neonatal Ed. 2016;101:F248-52

40. Hough JL, Shearman AD, Jardine LA, Davies MW. Humidified high flow nasal cannulae: current practice in Australasian nurseries, a survey. J Paediatr Child Health. 2012;48:106-13.

41. Manley BJ, Owen L, Doyle LW, Davis PG. High-flow nasal cannulae and nasal continuous positive airway pressure use in non-tertiary special care nurseries in Australia and New Zealand. J Paediatr Child Health. 2012;48:16-21.

42. Ojha S, Gridley E, Dorling J. Use of heated humidified high-flow nasal cannula oxygen in neonates: a UK wide survey. Acta Paediatr. 2013;102:249-53.

43. Iranpour R, Sadeghnia A, Hesaraki M. High-flow nasal cannula versus nasal continuous positive airway pressure in the management of respiratory distress syndrome. J Isfahan Med School. 2011;29:761-71.

44. Woodhead DD, Lambert DK, Clark JM, Christensen RD. Comparing two methods of delivering high-flow gas therapy by nasal cannula following endotracheal extubation: a prospective, randomized, masked, crossover trial. J Perinatol. 2006:26:481-5.

45. Collaborative Group For The Multicenter Study On Heated Humidified HighFlow Nasal Cannula V. Efficacy and safety of heated humidified high-flow nasal cannula for prevention of extubation failure in neonates. Zhonghua Er Ke Za Zhi. 2014;52:271-6.
46. Kugelman A, Riskin A, Said W, Shoris I, Mor F, Bader D. A randomized pilot study comparing heated humidified high-flow nasal cannulae with NIPPV for RDS. Pediatr Pulmonol. 2015;50:576-83.

47. Klingenberg C, Pettersen M, Hansen EA, et al. Patient comfort during treatment with heated humidified high flow nasal cannulae versus nasal continuous positive airway pressure: a randomised cross-over trial. Arch Dis Child Fetal Neonatal Ed. 2014;99:F134-7.

48. Osman M, Elsharkawy A, Abdel-Hady H. Assessment of pain during application of nasal-continuous positive airway pressure and heated humidified high-flow nasal cannulae in preterm infants. J Perinatol. 2015:35:263-7.

49. Lavizzari A, Colnaghi M, Ciuffini F, Et Al. Heated, Humidified High-Flow Nasal Cannula Vs Nasal Continuous Positive Airway Pressure For Respiratory Distress Syndrome Of Prematurity: A Randomized Clinical Noninferiority Trial. Jama Pediatr. 2016. Published online August 8, 2016. doi:10.1001/ jamapediatrics.2016.1243

50. Hegde D, Mondkar J, Panchal H, Manerkar S, Jasani B, Kabra N. Heated humidified high flow nasal cannula versus nasal continuous positive airway pressure as primary mode of respiratory support for respiratory distress in preterm infants. Indian Pediatr. 2016;53:129-33.

51. Leder SB, Siner JM, Bizzarro MJ, McGinley BM, Lefton-Greif MA. Oral alimentation in neonatal and adult populations requiring high-flow oxygen via nasal cannula. Dysphagia. 2016;31:154-9.

52. Shetty S, Hunt K, Douthwaite A, Athanasiou M, Hickey A, Greenough A. High-flow nasal cannula oxygen and nasal continuous positive airway pressure and full oral feeding in infants with bronchopulmonary dysplasia. Arch Dis Child Fetal Neonatal Ed. 2016;101:F408-11.

53. Konig K, Stock EL, Jarvis M. Noise levels of neonatal high-flow nasal cannula devices-an in-vitro study. Neonatology. 2013;103:264-7.

54. Roberts $C T$, Dawson JA, Alquoka E, et al. Are high flow nasal cannulae noisier than bubble CPAP for preterm infants? Arch Dis Child Fetal Neonatal Ed. 2014;99:F291-5.

55. Roberts CT, Manley BJ, Dawson JA, Davis PG. Nursing perceptions of highflow nasal cannulae treatment for very preterm infants. J Paediatr Child Health. 2014;50:806-10.

56. Fleeman $\mathrm{N}$, Mahon J, Bates $\mathrm{V}$, et al. The clinical effectiveness and costeffectiveness of heated humidified high-flow nasal cannula compared with usual care for preterm infants: systematic review and economic evaluation. Health Technol Assess. 2016;20:1-68.

57. Kotecha SJ, Adappa R, Gupta N, Watkins WJ, Kotecha S, Chakraborty M. Safety and Efficacy of High-Flow Nasal Cannula Therapy in Preterm Infants: A Meta-analysis. Pediatrics. 2015;136:542-53.

58. Ciuffini F, Pietrasanta C, Lavizzari A, et al. Comparison between two different modes of non-invasive ventilatory support in preterm newborn infants with respiratory distress syndrome mild to moderate: preliminary data. Pediatr Med Chir. 2014;36(4):88.

59. Shin J, Park K, Lee E, Choi BM. Humidified high flow nasal cannula versus nasal continuous positive airway pressure as an initial respiratory support in preterm infants with respiratory distress: a randomized, controlled noninferiority trial. J Korean Med Sci. 2017;32:650-5.

60. Campbell DM, Shah PS, Shah V, Kelly EN. Nasal continuous positive airway pressure from high flow cannula versus Infant Flow for Preterm infants. J Perinatol. 2006:26:546-9.

61. Miller SM, Dowd SA. High-flow nasal cannula and extubation success in the premature infant: a comparison of two modalities. J Perinatol. 2010:30:805-8.

62. Kang $W Q, X u B L$, Liu DP, et al. Efficacy of heated humidified high-flow nasal cannula in preterm infants aged less than 32 weeks after ventilator weaning. Zhongguo Dang Dai Er Ke Za Zhi. 2016;18:488-91.

63. Soonsawad S, Swatesutipun B, Limrungsikul A, Nuntnarumit P. Heated Humidified High-Flow Nasal Cannula for Prevention of Extubation Failure in Preterm Infants. Indian J Pediatr. 2017;84:262-6.

64. Kadivar M, Mosayebi Z, Razi N, Nariman S, Sangsari R. High flow nasal cannulae versus nasal continuous positive airway pressure in neonates with respiratory distress syndrome managed with Insure method: a randomized clinical trial. Iranian Journal Of Medical Sciences. 2016;41:494-500.

65. Abdel-Hady H, Shouman B, Aly H. Early weaning from CPAP to high flow nasal cannula in preterm infants is associated with prolonged oxygen requirement: a randomized controlled trial. Early Hum Dev. 2011:87:205-8.

66. Badiee Z, Eshghi A, Mohammadizadeh M. High flow nasal cannula as a method for rapid weaning from nasal continuous positive airway pressure. Int J Prev Med. 2015;6:33. 
67. Soonsawad S, Tongsawang N, Nuntnarumit P. Heated humidified high-flow nasal cannula for weaning from continuous positive airway pressure in preterm infants: a randomized controlled trial. Neonatology. 2016;110:204-9.

68. Tang J, Reid S, Lutz T, Malcolm G, Oliver S, Osborn DA. Randomised controlled trial of weaning strategies for preterm infants on nasal continuous positive airway pressure. BMC Pediatr. 2015;15:147.

69. Jhung MA, Sunenshine RH, Noble-Wang J, et al. A national outbreak of Ralstonia mannitolilytica associated with use of a contaminated oxygendelivery device among pediatric patients. Pediatrics. 2007;119:1061-8.

70. Iglesias-Deus A, Perez-Munuzuri A, Lopez-Suarez O, Crespo P, Couce ML. Tension pneumocephalus induced by high-flow nasal cannula ventilation in a neonate. Arch Dis Child Fetal Neonatal Ed. 2017;102:F173-F5.

71. Hegde S, Prodhan P. Serious air leak syndrome complicating high-flow nasal cannula therapy: a report of 3 cases. Pediatrics. 2013;131:E939-44.

72. Jasin LR, Kern S, Thompson S, Walter C, Rone JM, Yohannan MD. Subcutaneous scalp emphysema, pneumo-orbitis and pneumocephalus in a neonate on high humidity high flow nasal cannula. J Perinatol. 2008;28:779-81.

73. Hoffman SB, Terrell N, Driscoll CH, Davis NL. Impact of High-Flow Nasal Cannula Use on Neonatal Respiratory Support Patterns and Length of Stay. Respir Care. 2016;61:1299-304.

74. Taha DK, Kornhauser M, Greenspan JS, Dysart KC, Aghai ZH. High Flow Nasal Cannula Use Is Associated with Increased Morbidity and Length of Hospitalization in Extremely Low Birth Weight Infants. J Pediatr. 2016; 173:50-5 e1.

75. Roberts CT, Owen LS, Manley BJ, Davis PG, Australian, New Zealand Neonatal N. High-flow support in very preterm infants in Australia and New Zealand. Arch Dis Child Fetal Neonatal Ed. 2016;101:F401-3.

76. Shetty S, Sundaresan A, Hunt K, Desai P, Greenough A. Changes in the use of humidified high flow nasal cannula oxygen. Arch Dis Child Fetal Neonatal Ed. 2016;101:F371-2.

77. Soll RF, Edwards EM, Badger GJ, et al. Obstetric and neonatal care practices for infants 501 to $1500 \mathrm{~g}$ from 2000 to 2009. Pediatrics. 2013;132:222-8.

78. Nath P, Ponnusamy V, Willis K, Bissett L, Clarke P. Current practices of high and low flow oxygen therapy and humidification in UK neonatal units. Pediatr Int. 2010;52:893-4.

79. Chow SSW. Report of the Australian and New Zealand Neonatal Network 2014. Sydney: ANZNN; 2016.

80. Motojima Y, Ito M, Oka S, Uchiyama A, Tamura M, Namba F. Use of highflow nasal cannula in neonates: nationwide survey in Japan. Pediatr Int. 2016;58:308-10

81. Boyle MA, Dhar A, Broster S. Introducing high-flow nasal cannula to the neonatal transport environment. Acta Paediatr. 2017;106:1363.

82. Reynolds P, Leontiadi S, Lawson T, Otunla T, Ejiwumi O, Holland N. Stabilisation of premature infants in the delivery room with nasal high flow. Arch Dis Child Fetal Neonatal Ed. 2016;101:F284-7.

\section{Submit your next manuscript to BioMed Central and we will help you at every step:}

- We accept pre-submission inquiries

- Our selector tool helps you to find the most relevant journal

- We provide round the clock customer support

- Convenient online submission

- Thorough peer review

- Inclusion in PubMed and all major indexing services

- Maximum visibility for your research

Submit your manuscript at www.biomedcentral.com/submit

) Biomed Central 